\title{
COMMENTARY ON "THE SWING PHASE OF WALKING WITH ABOVE-KNEE PROSTHESES" BY DR. EUGENE F. MURPHY
}

\section{STEFANIA FATONE, PHD, BPO(HONS)}

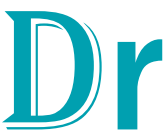

Eugene Murphy's tour de force article provided - a detailed and wellillustrated description of the various prosthetic knee mechanisms in use or in development in 1964 along with an understanding of the locomotor functions required of prosthetic knees based on the formidable gait analysis work of his compatriots Drs. Inman and Eberhart (p. 6-10). Fluid control remains a major component of current commercially available prosthetic knee joint technology, with major technological gains in the control of hydraulic resistance and the ability to do so throughout the gait cycle rather than just in swing phase, as described by Dr. Murphy.

While our technology has evolved, Dr. Murphy's insights about gait and the needs of the person with lower- limb amputation continue to ring true. The prosthetic knees in use and in development today try to more fully match the function of muscles that Dr. Murphy so aptly described as "brakes and motors" (p. 8), allowing not only for swing phase control as discussed by Dr. Murphy, but also improved function during stance and other mobility tasks. While many of the challenges faced by persons with transfemoral amputation have been resolved by commonplace use of hydraulic mechanisms and, in particular, microprocessor-controlled knees, some of the very same problems mentioned by Dr. Murphy, e.g., slower than normal walking speed, increased oxygen cost, and the high incidence of stumbles and falls, remain a focus of our research efforts to help improve the mobility of people living with transfemoral amputation.

Dr. Murphy presaged our ongoing challenges of simulating "the active functions of muscles as motors" (p. 9) and providing sensory feedback (p. 12). Powered prosthetic knees have recently emerged as commercial products. In these devices, sensors work through a microprocessor to control the actuation of a motor that can provide the active torque needed to perform functions like climbing stairs step over step or negotiating slopes with ease. More powered technology is on the horizon, with researchers integrating powered knee and ankle function and adding control input from residual-limb muscles. With such technologies in sight, perhaps we're closer than ever to answering Dr. Murphy's challenge of providing as much, if not more, sensory feedback than a peg leg! 